\title{
Alternate reality games (ARG) as innovative digital information sources
}

Purpose The article presents the gathering, integration and analysis of digital information sources for the creation of a conceptual framework for ARGs. ARGs hold potential for libraries, education, healthcare and many other sectors.

Design/methodology/approach - Case studies were performed on three previously played ARGs to create case reports. The various digital information sources for each game, sourced from multiple media, are compiled into a chronologically ordered game narrative which formed the case reports. The focus of the article is on the analysis of the case reports using constant comparative analysis to identify categories and subcategories. Relationships are established, based on each game, between the categories and sub categories to inform the creation of game diagrams. The game diagrams are then combined to create a conceptual framework that describes the functioning and components of an ARG.

Findings - The conceptual framework effectively described the types of information found within an $A R G$ as well as how these different categories of information interact and link to one another. The framework also provides an abstract description of the components of ARGs, namely narrative, game actions and community.

Originality/value - The conceptual framework produced by the analysis enables an understanding of ARGs and how they are played and designed. Insight into how to analyse ARGs based on the information generated for the play of the game by both the players and the game designers is gained. Where other studies have provided insight into the phenomena of ARGs, this study focuses on constructing a conceptual framework of ARGs using the information generated by the game.

Keywords Alternate reality games; Multiple case studies; Constant comparative analysis; Conceptual framework; Game design theory; Digital information sources

Paper type Research paper

\section{Introduction}

Alternate reality games (ARGs) are complex narrative driven transmedia games that require deep player engagement. The games rely heavily on player participation and thus produce player created content. The game content (created by the game creators) and player created content (created while the game is played) form the digital information sources for the play of the game.

The article presents firstly the type of information sources found when analysing ARGs. The sources generated by the games are various and spread over multiple media. The information was also generated by different people, from players of the game to the creators of the game. The article then shows how the information was compiled to form a complete narrative whole that is chronologically correct. An in depth analysis of this complete narrative is then done to establish the type of phenomena found within the game (through categorisation) and how the phenomena relate to one another (through creating diagrams). Finally the diagrams are compiled into game summary diagrams which are abstraction of the individual games. The summary diagrams then informs the creation of a conceptual framework for ARGs.

\section{Background}

Various authors have published about ARGs and how they work since their advent in 2001. To effectively analyse ARGs to develop a conceptual framework one must first understand what ARGs 
are from the existing literature. A theoretical framework will help inform the analysis of case studies done on specific games and provide a solid academic basis for the conceptual framework.

\section{Characteristics of alternate reality games}

Alternate Reality Games (also known as ARGs) is a genre of games that has grown beyond the boundaries of entertainment. The nature of ARGs is so rapidly changing that it is very difficult to give a single definition as it will limit the understanding of the individual games. It is thus rather more effective to provide certain characteristics found in ARGs and discuss them.

First and foremost, ARGs are games. They are played by players and they are enjoyed for entertainment purposes. The player is never forced to participate in the activities of the game and do so purely for entertainment. Aside from being a game, ARGs has very specific characteristics.

ARGs make extensive use of collective intelligence (Kim et al., 2009; McGonigal, 2003a). The players are required to embark on collective problem solving (Bono and Breeze, 2008; Bonsignore et al., 2012; Hakulinen, 2013; Kim et al., 2009; Örnebring, 2007) and are sometimes referred to as the collective detective (unfiction inc, 2002). Part of the collective intelligence is the fact that players will have different and overlapping literacies, all required to solve the problems the game presents.

Leveraging the collective detective, the players need to engage in collective play (Gurzick et al., 2011; Hakulinen, 2013; Kim et al., 2009; McGonigal, 2003a) and in that way advance the game (Bonsignore et al., 2012; Dena, 2008). The act of the players to uncover, collect, interpret and reassemble the game information is a collaborative task (Hansen et al., 2013).

An ARG should be an immersive game (McGonigal, 2003a). Immersion entails that the player is participating with the game and the space of the game on a deep level. The player should be enthralled by everything the game presents to them.

Another key characteristic of ARGs is the use of multiple media (Martin et al., 2006). The use of cross media (unfiction inc, 2002) is one of the unique characteristics of ARGs. ARGs use multimedia to a large extent (digital media) but also employ multiple types of media (Hansen et al., 2013; Kim et al., 2008; McGonigal, 2003a, 2004). The usage of "real technologies" like email, letters, packages and other physical media adds to the effectivity of the integrated reality of the game (Bono and Breeze, 2008; Dena, 2008; McGonigal, 2003a). The undefined communication media is also a strength of an $A R G$ as the players can decide what would be the best way to communicate. The community can form naturally around specific communication technologies.

With the extensive use of multiple media as well as the requirement of a community to employ their collective intelligence, collaboration is an obvious characteristic of ARGs (Gurzick et al., 2011; Kim et al., 2009; McGonigal, 2003a; unfiction inc, 2002). Players and the various player groups in the community must collaborate on all tasks of a game for the game to move forward (Dena, 2008). Gameplay tasks can involve solving puzzles, collecting information, disseminating the information, compiling new information and hypothesis creation (Hakulinen 2013; Hansen et al. 2013).

The narrative is an integral part of the ARG and is the driving force behind the game. The players interact with the narrative and through their actions, compile the distributed narrative and create their own content as well that forms part of the game narrative (Dena, 2008; Hansen et al., 2013; Kim et al., 2008; Martin et al., 2006; McGonigal, 2003a; unfiction inc, 2002). The narrative can be both embedded and emergent (Salen and Zimmerman, 2003, p. 383). The embedded narrative (designed narrative) can be superseded by the emergent narrative. With an ARG, the emergent narrative is thus most evident (Chess and Booth, 2014). The content creation and the player created narrative are a result of collaboration and a manifestation of the collective intelligence in the game. ARGs make use 
of transmedia storytelling where the narrative of the game is distributed across multiple media (Bonsignore et al., 2012; Dena, 2008; Hansen et al., 2013).

The players interact with game characters who in many cases are manifestations of the puppet masters (the game designers) in the game. This interaction can influence the narrative of the game by adding the player created narrative (through player action) into the game narrative.

ARGs create an alternate reality that is a combination of the game world and the player's world (Dena, 2008; Gurzick et al., 2011; Kim et al., 2008; Martin et al., 2006; McGonigal, 2003a; Örnebring, 2007; Szulborski, 2005). This reality is integrated into the player's reality through various methods. One of the methods to achieve integration into reality is to use "real world technologies" like email, web sites, faxes, letters and physical artefacts. Virtual immersion is achieved by the combination of "real world technologies" and the game world (McGonigal, 2003a). By doing this, the frame of the game is expanded beyond the traditional game boundaries thus including reality into the game space (Chess and Booth, 2014). It is also important to note that an ARG is played in real time. This means that the players experience the game events as they unfold in real time.

To a large extent, the players are engaged in puzzle solving activities or challenges prompted by the game which can take the form of scavenger hunts. These actions taken within the ARG context, are considered game actions (formally and informally, game prompted or player initiative). By completing these challenges and solving the puzzles the players uncover hidden information that can be narrative, more puzzles or game artefacts to name but a few.

Table 1 shows the characteristics of an ARG based on author contribution. In no way is the list of authors exhaustive but is effective in highlighting the unique characteristics of ARGs.

Legend: Bono and Breeze (1), unfiction inc (2), Martin et al. (3), McGonigal (4), Kim et al. (5), Gurzick et al. (6), Szulborski (7), Örnebring (8), Dena (9), Bonsignore et al. (10), Hansen et al. (11), Hakulinen (12), Chess \& Booth (13)

\begin{tabular}{|c|c|c|c|c|c|c|c|c|c|c|c|c|c|}
\hline Characteristics of an ARG & 1 & 2 & 3 & 4 & 5 & 6 & 7 & 8 & 9 & 10 & 11 & 12 & 13 \\
\hline $\begin{array}{l}\text { Collective Intelligence/Collective problem } \\
\text { solving/ } \\
\text { Collective detective }\end{array}$ & $X$ & $x$ & & $\mathrm{X}$ & $x$ & & & $x$ & & $x$ & & $x$ & \\
\hline Collective play & & & & $\mathrm{X}$ & $\mathrm{X}$ & $\mathrm{X}$ & & & $\mathrm{X}$ & $\mathrm{X}$ & $\mathrm{X}$ & $\mathrm{X}$ & \\
\hline Immersive game & & & & $\mathrm{X}$ & & & & & & & & & \\
\hline $\begin{array}{l}\text { Cross media/ Multiple media/ Multiple } \\
\text { communication technologies }\end{array}$ & $\mathrm{X}$ & $\mathrm{X}$ & $\mathrm{X}$ & $\mathrm{X}$ & $\mathrm{X}$ & & & & $\mathrm{X}$ & & $\mathrm{X}$ & & \\
\hline Collaborative & $\mathrm{X}$ & & & $\mathrm{X}$ & $\mathrm{X}$ & $\mathrm{X}$ & & & $\mathrm{X}$ & & $\mathrm{X}$ & $\mathrm{X}$ & \\
\hline $\begin{array}{l}\text { Narrative/Interactive narrative/Content } \\
\text { creation/Distributed narrative }\end{array}$ & $\mathrm{X}$ & $\mathrm{X}$ & $\mathrm{X}$ & $\mathrm{X}$ & $\mathrm{X}$ & & & & $\mathrm{X}$ & & $\mathrm{X}$ & & $\mathrm{X}$ \\
\hline $\begin{array}{l}\text { Virtual Immersion/Integrated reality/ } \\
\text { Alternate reality }\end{array}$ & $\mathrm{X}$ & & $\mathrm{X}$ & $\mathrm{X}$ & $\mathrm{X}$ & $\mathrm{X}$ & $\mathrm{X}$ & $\mathrm{X}$ & $\mathrm{X}$ & & & & $\mathrm{X}$ \\
\hline Real time & $\mathrm{X}$ & & $\mathrm{X}$ & $\mathrm{X}$ & & & & & $\mathrm{X}$ & & & $\mathrm{X}$ & \\
\hline Transmedia storytelling/ fiction & & & & & & & & & $\bar{X}$ & $\mathrm{X}$ & $\mathrm{X}$ & & \\
\hline $\begin{array}{l}\text { Interaction between producer/game and } \\
\text { player/ puppetmaster }\end{array}$ & & $\mathrm{X}$ & & & & & & & & $\mathrm{X}$ & & $\mathrm{X}$ & \\
\hline $\begin{array}{l}\text { Solve puzzles/ challenges/ scavenger hunt } \\
\text { like }\end{array}$ & $\mathrm{X}$ & $\mathrm{X}$ & & & & & & & & & $\mathrm{X}$ & $\bar{X}$ & \\
\hline
\end{tabular}

Table 1: Characteristics of an ARG 
Taking the above characteristics, a theoretical framework for the analysis of ARGs can be created by condensing the characteristics into components.

\section{Theoretical framework for the analysis of ARGs}

The above characteristics show that ARGs require collective problem solving and collective intelligence on the part of its player community. This community then engages in collective play which requires collaboration on the part of the players and player groups. The literature also identified that ARGs extensively use multiple media for both gameplay and player communication. The use of multiple types of media is one of the characteristics that enable ARGs to integrate into the players' reality and create virtual immersion. The ARG runs in real time, again aiding integration into player reality as well as resulting in an unclear and unlimited game space. Finally, an ARG is a form of transmedia storytelling that spreads the narrative over different media and requires the players to both interact with it, compile the various pieces collected over time and even enable the players to become content creators. The player interaction with the game can result in changes in narrative and even in gameplay changes.

The literature shows that three components are of primary importance:

- The narrative component - including how games deal with narrative (engagement and participation on a formal level) and how ARGs deal with narrative (as with games but adding onto it an experiential framing)

- Game action - as defined by the game design theory

- Community and Interaction - how players interact and participate with ARGs.

In the IGDA ARG SIG whitepaper, Andrea Phillips in Martin et al. (2006) wrote about ARG methods and mechanics. According to the whitepaper:

The basic recipe for an ARG could be boiled down to Exposition + Interaction + Challenges. Each of these components must be present for any given game to be widely accepted as an $A R G$, but the amounts in which they must be represented and the weight on each leg of the tripod vary widely from game to game.

(Martin et al., 2006, p. 31)

The three components defined in this article are similar to the three defined in the whitepaper. The narrative component is exposition, game action is challenges and community and interaction is interaction.

Combining the characteristics identified by the literature into components produced Table 2 below. 


\begin{tabular}{|c|c|c|c|}
\hline & & \multicolumn{2}{|l|}{ ARGs } \\
\hline $\begin{array}{l}\text { Narrative } \\
\text { component }\end{array}$ & $\begin{array}{l}\text { Game narrative/ } \\
\text { Story world }\end{array}$ & \multicolumn{2}{|c|}{$\begin{array}{ll} & \text { Transmedia storytelling/ fiction } \\
\text { - } & \text { Narrative/ Interactive narrative/ Content creation/ Distributed narrative. }\end{array}$} \\
\hline \multirow[b]{2}{*}{ Game Action } & & - Solve puzzles/ challenges/ scavenger hunt like. & \\
\hline & Mechanics & $\begin{array}{l}\text { - Cross media/ Multiple media/ Multiple } \\
\text { communication technology - The media } \\
\text { facilitates the mechanics of the game. } \\
\text { - Virtual Immersion/ Integrated reality/ Alternate } \\
\text { reality. } \\
\text { - Real time. }\end{array}$ & \multirow[t]{2}{*}{$\begin{array}{c}\text { Alternate reality - } \\
\text { because of these } \\
\text { characteristics the } \\
\text { game creates an } \\
\text { alternate reality. }\end{array}$} \\
\hline \multirow{3}{*}{$\begin{array}{l}\text { Community } \\
\text { and } \\
\text { interaction }\end{array}$} & & $\begin{array}{l}\text { - Immersive game - the players interact with the } \\
\text { game and one another in a way that promotes } \\
\text { immersion. }\end{array}$ & \\
\hline & Interaction & \multicolumn{2}{|c|}{ - Interaction between producer/game and player/ puppet master. } \\
\hline & Player collaboration & \multicolumn{2}{|c|}{$\begin{array}{l}\text { - Collaborative. } \\
\text { - Collective play. }\end{array}$} \\
\hline
\end{tabular}

Table 2: ARG theory - components/categories

\section{Collaboration - the player community}

The player community in an ARG is one of the most important components to understand and consider when analysing and designing ARGs. The basic interaction of players with a game and one another is compounded in an ARG because of the requirement of collective intelligence, the collaboration for gameplay and the way collective play functions.

The puzzles in an ARG are complex and require various levels of expertise. This requires the players to function as a collaborative group (McGonigal, 2003a). The collaboration by the players include sifting through large amounts of information collected from different locations at different times and then compiling it into a cohesive whole as well as real time coordination of player effort (Kim et al., 2008; McGonigal, 2007). Kim, Allen and Lee (2008), McGonigal (2003b) and Dena (2008) describe the tasks of the community as one of finding clues, solving puzzles, disseminating the solutions and gathered information and coordinating with one another.

This self-organizing, self-coordinating player collective needs to complete challenges to move the ARG forward in terms of gameplay and narrative. The player community forms around the play of the ARG and can also form subgroups. These subgroups will form around certain challenges or puzzles, geographic locations or player expertise (Gurzick et al., 2011). After solutions are found the subgroup will dissolve back into the community. According to Gurzick et al. (2011, p. 177), players in these communities have three activities: collecting the information pieces and developing theories, discussing the way the players gather the information and how valid the information is, and finally, including the knowledge formed from this process in the collectives' shared wisdom.

\section{Narrative - Interactive narrative and the player as producer}

The narrative in an ARG is unique when considering how traditional games use narrative. The narrative in games primarily appears as embedded or emergent narrative (Salen and Zimmerman, 2003, p. 383). In ARGs the emergent nature of the narrative is core to ARG narrative. In ARGs players construct their own narrative when disseminating and compiling the narrative pieces (information) found during the game and in doing that becomes producers within the game (McGonigal, 2003a). 
The narrative in ARGs are also fragmented (Dena, 2008) and distributed through various media to be discovered at different times (McGonigal, 2007). These narrative pieces are not linked "hyper - or intertextually" (Dena, 2008) which means the compilation of "the whole story" and filling in of the gaps (Gurzick et al., 2011) is up to the community.

Dena (2008) describes content created by the player community in an attempt to compile the narrative, and as a response to the segments provided by the game designers, as becoming the main product of consumption. Kim et al. (2009) go so far as saying that the player-created segment, the "collective story" supplants the main story and becomes the primary narrative.

\section{Game actions in ARGs}

The game actions (or gameplay) in an ARG can take on many forms. Game actions in an ARG are unique in the way they are implemented, managed and interacted on by the players, and how they are targeted to the player community.

Examples of game actions in ARGs can be:

- Puzzles (Hakulinen, 2013) - puzzles can range from simple riddles to complex cryptography and steganography. The challenge behind the puzzle from the perspective of the game designers is that it should only be solvable by a group. This can be done by increasing the difficulty, requiring wide and varied knowledge or even require a number of people to complete (no knowledge, just collaboration).

- Scavenger hunt (Bonsignore et al., 2012) - the scavenger hunt is a chain of actions the players need to take to get to an end point. The different parts of the hunt can contain puzzles that must be solved by the players or it can be simple "go to" instructions left by the puppet masters to the next part.

- Gameplay - this implementation can be traditional gameplay elements interwoven into the game that require the players to complete game like tasks to progress through the ARG.

These examples are in no way exhaustive. Understanding what tasks games set forth for players to complete, the ARG implementation of game actions is easy to see.

\section{The salient issues in the literature}

The background provides context of ARGs and identifies the primary components that can be found in ARGs. The literature also shows the type of information available in an ARG and how the players consume it. The consumption of this information results in the players compiling the narrative as well as producing their own narrative.

\section{Research Approach}

With the theory provided, a brief discussion of how the case studies where compiled, taking into consideration the information available in ARGs, is required.

\section{Method - Multiple case studies}

Multiple case studies (Yin, 2013) were performed based on different ARGs that have been played in the past. Due to the fact that an ARG can only be played once and that it is a phenomenon that existed for a limited time, the case studies could only be done on various information sources gathered after the fact. 


\section{Selecting the cases}

For this article, three cases were selected. The unit of analysis for each case study was "An ARG that was played until its end". The three cases were selected using a priori criteria selection. A set of criteria was developed to identify possible candidates for the cases (Table 3).

\begin{tabular}{|c|c|c|c|c|c|}
\hline 1 & ARG completeness & 2 & Live game sites & 3 & Timeline \\
\hline 4 & Complete narrative & 5 & Variety of game actions & 6 & Detailed game guide \\
\hline
\end{tabular}

Table 3: A priori criteria for case selection

1. The ARG must have been run until completed. Games that were abandoned during play could not be included. ARGs that were considered failures could also not be included in the selection.

2. The ARGs should have had live game sites. These were the sites (can be websites, archives, download links etc.) that were used during the play of the game.

3. The ARGs should have contained an accurate timeline. Data sources should have been available to establish an accurate timeline for the game.

4. The ARG should have had a complete narrative. The play of the game revealed a clear narrative which the players could effectively compile during the play of the game.

5. The ARG should have contained a variety of game actions. The game should not have primarily focused on scavenger hunts or online puzzles.

6. A detailed game guide should have been available for the game. The game guide was used as the primary data source for the cases.

After establishing these criteria, online archives of ARGs were consulted. Interactive sampling was used to select cases that adhered to the criteria defined above. The ARG community consistently discussed certain ARGs as the benchmark for future ARGs. The games were consulted based on their popularity and how the ARG community refer to them.

The number of ARGs played since 2001 is vast and in no way were all the games investigated as candidates for the analysis. As previously mentioned, the games were selected based on the a priori criteria listed in Table 3 but also based on how the community discuss them or reference them.

The following cases were selected:

1. "I Love Bees" - a promotional ARG created in 2004, by Microsoft, for the promotion of the launch of the Halo 2 digital game.

2. "Year Zero" - a promotional ARG created in 2007, by 42 entertainment, for the promotion of a music album titled "Year Zero" for the artist "Nine Inch Nails".

3. "Number 13" - a grassroots ARG created in 2010 , by post graduate students at the University of Pretoria, as a capstone to Multimedia studies at fourth year level.

Two of the cases selected adhered to all of the criteria and were identified through interactive sampling ("I Love Bees" and "Year Zero"). The third case was selected as a possible example of an outlier. The third case, "Number 13", was selected for the purpose of identifying exceptions to the propositions (discussed in the next section). The researcher was closely involved in the development of the "Number 13" game. That being said, "Number 13" still adhered to the a priori criteria and no internal knowledge or sources (puppet master knowledge, internal design documentation, puzzle solutions etc.) was used during the study. All information reported for "Number 13" from the player perspective was gathered from player created sources (guide/wiki and game sites). 


\section{Objectives and propositions of the case studies}

The following questions were used to guide the objectives of the case studies:

- How can the components/categories of an ARG be identified?

- What components/categories were identified?

- How are the components/categories of an ARG sub categorized?

- What structures are formed by linking according to the relationships between the components/categories and subcategories?

How can these structures be used to develop a conceptual framework? The categories in ARGs were primarily informed by the exploration of the literature and were discussed earlier in the article.

Using these categories and subcategories to categorise game events will help to identify, in an abstract way, how these components interact with one another as well as the link between them. The one component can lead to another which may lead to another component. Specific components may also interact with more than one other component. This type of abstraction can lead to structures forming. These structures can appear to be repeating and form patterns that can be used to identify a design framework.

Exploring the formation of the structures and looking for patterns in these structures can lead to another layer of abstraction where an ARG can be described by using a combination of these structures. This will then lead to the ability to define a design framework for the design of an ARG as well as a framework that can aid in the analysis of an ARG based on game design theory.

The objective of the case study was to produce accurate game summaries that could then in turn, through analysis, produce the categories and subcategories that will be used to create the game structures. These structures will then enable the formulation of the conceptual framework. The analysis relies heavily on the accuracy and completeness of the game summaries, which will be the results of the multiple case studies.

\section{Data sources used for the multiple case studies}

During the study of the three ARGs, a parallel had to be found between the traditional sources of evidence and the sources available specific to an ARG. Because an ARG is only run once most of the times, a heavy reliance was placed on first-hand accounts from the perspective of players.

Game guides are written by specific players during the play of the game. These players are usually very active in the game and tend to consolidate player experiences and details of the game into a single document. This document or game guide serves as a first-hand account from the perspective of the guide writer (who is also a player).

Where information is lacking or more details about player-specific interaction is missing, the game forums and player forums can be consulted. These forums are asynchronous discussions about very specific events, puzzles or narrative. Forums can serve as a form of transcribed conversation between players, read by the researcher after the fact. For the sake of this article, game forums and player forums will serve as second-hand accounts from the perspective of the researcher. These sources of evidence could still be classified specific types of data sources.

\section{Documentation - game content and player created content}

Documentation produced by the players and puppet masters were used as one of the sources of evidence during the studies of the ARGs. These documentation sources included game sites created by the puppet masters, player-created game sites and game site content, player forums and communication channels. 
The game guides, written by one of the active players were analysed as documents. The game guides were written during the play of the game and were a collection of player experiences and conversations between active players. Guides served as first-hand accounts of the games (see the previous section on data sources). The game guides served as a formal form of documentation.

Game forums and communication media (player forums) were also used as a documentation data source. The amount of data produced by the players was vast. By going through that data, and looking for data dealing with specific instances, the researcher could create context for specific events/actions during the game. As explained previously, these player-created data sources (game forums and player forums) would serve as second hand accounts from the perspective of the researcher. The game and player forums served as an informal form of documentation.

\section{Interviews - asynchronous internet based discussions (forums, wiki's etc.)}

Interviews are usually done with people closely involved with the case that is being studied. The interviewer can ask questions guided by the research objectives and in that way produce content that can then be analysed. During the study of the three ARGs, interviews were not possible as the games were played in the past and player contact information is near impossible to collect because of the anonymous nature of the internet. Even though the researcher had no control over what the players wrote in their discussion on the game forums and player forums (the informal documentation), the forums discussions can be treated as an abstract form of "interview". They can still enlighten the researcher about very specific phenomena and in that way create context as with a traditional interview.

The data sources used for interviews are ex post facto because they are not traditional interviews as they are not live.

Archival records - digital information sources (game websites, images, videos, game guides) Archival records for the ARGs were found at various locations. Most of the archived artefacts such as game puzzles, websites, images, videos, live recordings and audio files created for the games were stored on the guide sites. Where archival records were missing, live game sites were consulted as well as media storage sites.

In the analysis of the ARGs, all documentation, both formal and informal, were also considered archival records. Data sources were treated similarly as traditional data sources but in the end, all the records used during the game analysis were archival records.

\section{Direct observations - videos and audio recordings of players playing}

Direct observation came in the form of the informal documentation (game and player forums). The documentation also included videos and recordings of players completing game actions and participating in "power plays". Because of the way the forums archived the player conversations, reading through these records served the same purpose as observing the same discussion between the players. This source of evidence allowed the researcher to observe the players participating in very specific $A R G$ events. Viewing the videos of the players interacting with one another provided insight into the interaction between the players. All of these sources (video and forums) are ex post facto therefore are not traditional direct observations because they are not live.

\section{Linking the data sources to the propositions and goals}

The data sources were used to establish a chronological and narrative flow for the game. Each of the types of sources were used to confirm information about the game. For example, when a clear timeline could not be established from a specific section in the game guide, the primary discussion medium was consulted to establish a clearer timeline as those sources usually contained date and time information. If the guide description of a game action, specifically a puzzle, was not clear enough, the live sites were consulted (the sites that were still available) for clarity. 
By compiling the game summaries using the above data sources, a more accurate and detailed explanation of the phenomena within the game could be provided. With a detailed game summary that is chronologically accurate, detailed from both player and guide writer perspective and augmented from existing game sites, the analysis of summary could provide the researcher with a detailed understanding of the game. The game summary can then accurately assist in answering the research questions: establishing categories and subcategories and identifying the relationships between the phenomena and their categories and subcategories.

Data sources were not exclusively used for specific tasks. The sources were consulted to provide clarity so that the research objectives could be reached. The decision whether to categorize a specific part of the case narrative was based on the fact that all sources were used to provide as clear as possible picture of the game flow.

\section{Collecting the evidence}

With the three ARGs, the type of information available was different from what would usually be gathered during a case study. The previous section on data sources provided explanation on what data sources are available for ARGs, and how they will be treated during the study. The data sources were used to construct the complete game narrative. Data from one source was used to confirm data from another source where ambiguity was found (Shenton, 2013, pp. 251-260).

The analysis of existing data from informal sources such as can be found in ARGs is not without precedent. Shenton (2013) explained that these data sources could be used as background information but also as the primary source of information for specific studies. Certain types of documents could even be used as if they were transcripts produced by interviews and analysed using document analysis (Shenton, 2013). The weakness of using these types of sources is that the researcher could not interfere in the gathering of the information. The researcher could not change the direction of conversations or ask more details about specific points made during discussions.

In the case of the ARGs, the information was created purely for recording purposes so people could later consult the sources and have a clearer idea of how the game was played, who played it, how it was played and how long it took. Selecting the three ARGs based on the provided criteria enabled the researcher to confirm some of the information created by the players as well as fill in omitted information from game sources because most of the game sites were still live. The usage of the "logs" also enabled the researcher to see more details on how the players interacted with one another as well as see how they came to solve certain challenges during the game.

These various sources in the end resulted in a more complete and accurate portrayal of the game in terms of its narrative, game actions and player participations than would have been the case if these sources were on their own. 


\section{Qualitative analysis using constant comparative analysis}

After the complete game narrative and chronological order was established, the games were analysed using a technique used in grounded theory. Using the constant comparative analysis technique results in the data constantly being compared with all the other similar pieces of data to "develop conceptualization of the possible relations between various pieces of data" (Pickard, 2013, pp. 267-281). During the analysis, categories emerged from the data. "Microanalysis", which was used during this study, is the line-by-line examination of the date (Picard, 2013, pp. 270). The "microanalysis" consists of open coding, axial coding and selective coding (Strauss and Corbin, 1998) and was used to develop and refine the categories based on the phenomena in the data.

\section{Open coding}

Open coding of the three ARGs produced the basic categories. These developed categories are similar to the components identified in the literature review. As Pickard (2013, pp. 267-281) stated, some of the phenomena will resemble salient issues in the existing work.

\section{Axial coding}

In the study of the three ARGs, this phase enabled the identification of links between the different components in each category. These links are extremely important and have a direct influence on game flow. The patterns identified through observing the phenomena and their links enabled the identification of structures that were repeated throughout each game. Each component could interact with another component in various ways, but by looking at the raw data (the game flow) in the depth required for microanalysis, these patterns repeated multiple times over the period of the game.

\section{Selective coding}

In the three case studies, the core categories were primarily identified through the literature review. The core categories did manifest in the third phase of microanalysis. Identifying the core categories in the third phase enabled the researcher to equate the emergent core categories to the existing salient issues in the literature.

Using microanalysis enables the researcher to build theory, handle masses of raw data, consider alternative meanings of the phenomena as well as identify, develop and relate concepts that "are the building blocks of theory" (Strauss and Corbin, 1998, p. 13)For the specific analysis of the data collected for the three ARGs, this method proved to be most appropriate as the huge amount of data available for each game required this researcher to iterate through each ARG multiple times and through each iteration new phenomena became evident and their relationships with one another. Identifying the building blocks of the theory also assisted this researcher in proposing the design framework.

\section{Developing the instruments}

Each of the ARGs selected for the individual case studies had to adhere to certain selection criteria. By adhering to these criteria, each ARG had a huge amount of raw data that had to be collected, ordered and summarised. The process was the same during the study of each ARG. The process can also be repeated on different ARGs that also adhere to the selection criteria.

Before each study started, it was ascertained each case adhered to the selection criteria. Each case had a complete game guide, live game sites, archived records for most game puzzles and assets, records of player communication and a basic timeline for the game (extracted from the guide). The process followed during each case study was as follows:

- Create the game summaries

- Establish narrative flow for the game

- Establish an accurate timeline for the game 
- Analyse the summary using constant comparative analysis

- Follow the three phases of microanalysis

After the process was followed for each ARG, the microanalysis also took place over all three summaries specifically to verify that all phenomena identified in all three cases could be placed in the core categories and their respective subcategories.

\section{Creating the game summary}

The game summaries were developed using the raw data available for each game. These summaries were also used as a source of evidence during analysis.

\section{Establish narrative flow for the game}

The guide for each game was used as the primary source of data during the creation of the summaries. To establish narrative flow the guide was consulted and where gaps were found in terms of narrative they were filled in using secondary sources such as player communications or game sites:

- "I Love Bees" - http://www.wonderweasels.org/apiary/guide.htm

- "Year Zero" - http://www.wonderweasels.org/yearzero/guide/guide.html

- "Number 13" - http://num13.pbworks.com/

The guides were written as first person accounts. Each guide author wrote from their perspective and included content they experienced or encountered on the player communications. Other players would have provided the guide writer with content if he/she was not aware of certain events. Where this information was not sufficient, secondary data sources were consulted to "fill in the gaps".

The guide writers also did not always include the full description of certain game assets or game actions. The details for these assets or game actions were found on the live game sites that were still accessible.

\section{Establish an accurate timeline for the game}

As mentioned previously, the guide writers wrote the guides from a player perspective and in some cases during the game, they omitted specific mention of when the events occurred or which event occurred after which event. In some cases the guides were divided into phases and weeks.

To make sure each game was divided into weeks and phases accurately, efforts were made to establish when each reported event, game action or discovery took place. To successfully accomplish this, the live game sites and player communication were consulted. Specifically the logs for these sources (where available). This enabled the researcher to not only construct the game timeline in terms of weeks and phases but also attach dates to the events.

Efforts were made to create an accurate timeline and establish chronology of events. Doing this enabled the analysis to produce accurate relationships between the identified phenomenon and categories. Knowing what phenomenon proceeded which was extremely important for the analysis.

\section{Analysing the game summaries - The categories and their respective sub categories}

Analysis of the game summaries took place after they were compiled. The detailed game summaries can be found in De Beer (2015). During each phase of microanalysis, the summaries were refined and structured so that they accurately reflected the game flow. Each piece of the game recounted in the summary was categorised based on the categories and subcategories identified during the microanalysis. The categories were produced by analysing the raw game data used to create the summaries. The creation of the summaries also enabled further analysis which produced more categories and subcategories. Establishing validity of the categories also resulted in the further refinement of the summaries. 
Table 4 - 7 shows the categories produced during the analysis of the raw data as well as during the creation of the game summaries. Each category will be described briefly and the symbol representing the category or subcategory will be provided.

Figure 1 provides an outline of how the ARGs' phenomena were categorised.

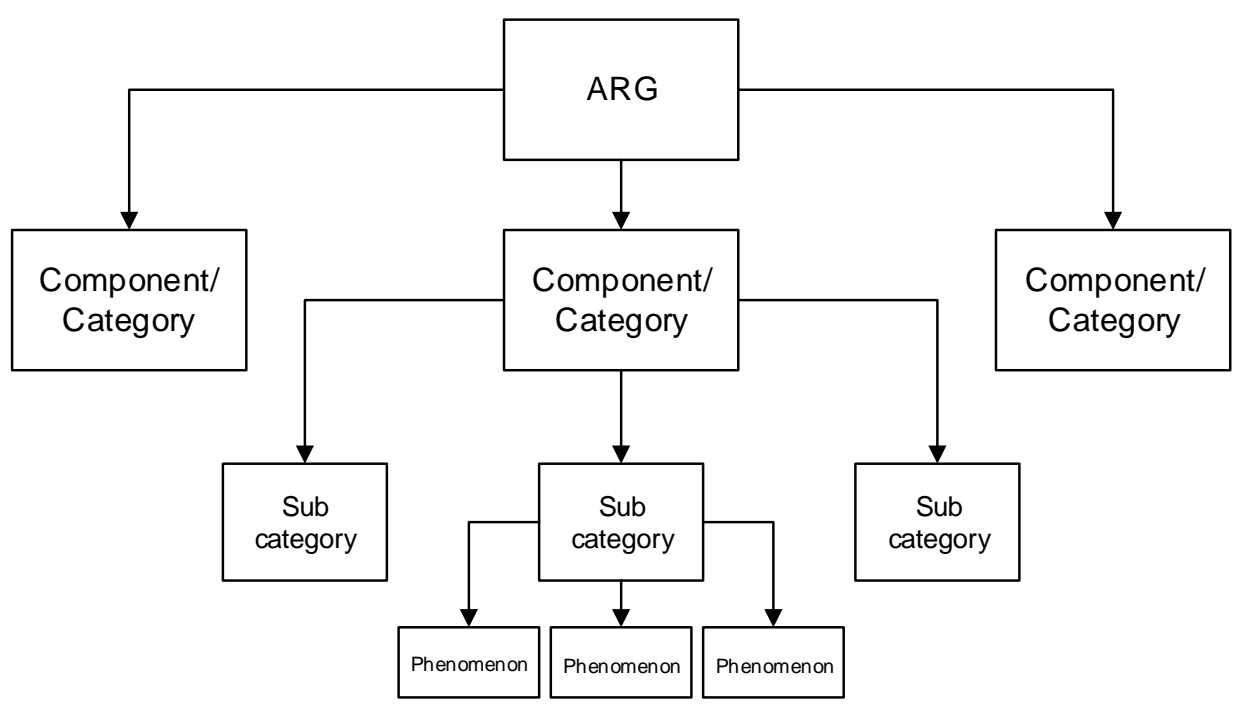

Figure 1: Categorising the phenomena in each ARG.

\begin{tabular}{|c|c|c|}
\hline Category & Symbol & Criteria \\
\hline Narrative & Narrative & $\begin{array}{l}\text { The narrative category encapsulates everything narrative from } \\
\text { the game. The subcategories compiled during the analysis } \\
\text { identified unique functionality of the individual narrative pieces. }\end{array}$ \\
\hline Subcategory & Symbol & Criteria \\
\hline Narrative hook & Narrative hook & $\begin{array}{l}\text { The narrative hook provided a piece of narrative that then linked } \\
\text { to another component. This can be a narrative piece, a lead-in } \\
\text { mechanism or a puzzle. }\end{array}$ \\
\hline Narrative reward & \begin{tabular}{|l|} 
\\
Narrative reward
\end{tabular} & $\begin{array}{l}\text { The narrative reward is a piece of narrative given to the players } \\
\text { as a reward for game participation. The narrative reward can } \\
\text { contain narrative hooks. }\end{array}$ \\
\hline
\end{tabular}




\begin{tabular}{|l|l|l|}
\hline Narrative piece & $\begin{array}{l}\text { The narrative pieces are provided to the players throughout the } \\
\text { game. This can be in the form of game updates on a regular } \\
\text { schedule or narrative provided to the players to further the } \\
\text { game context. Narrative pieces can contain narrative hooks. }\end{array}$ \\
\hline Narrative piece
\end{tabular}

Table 4: Subcategories of the narrative category

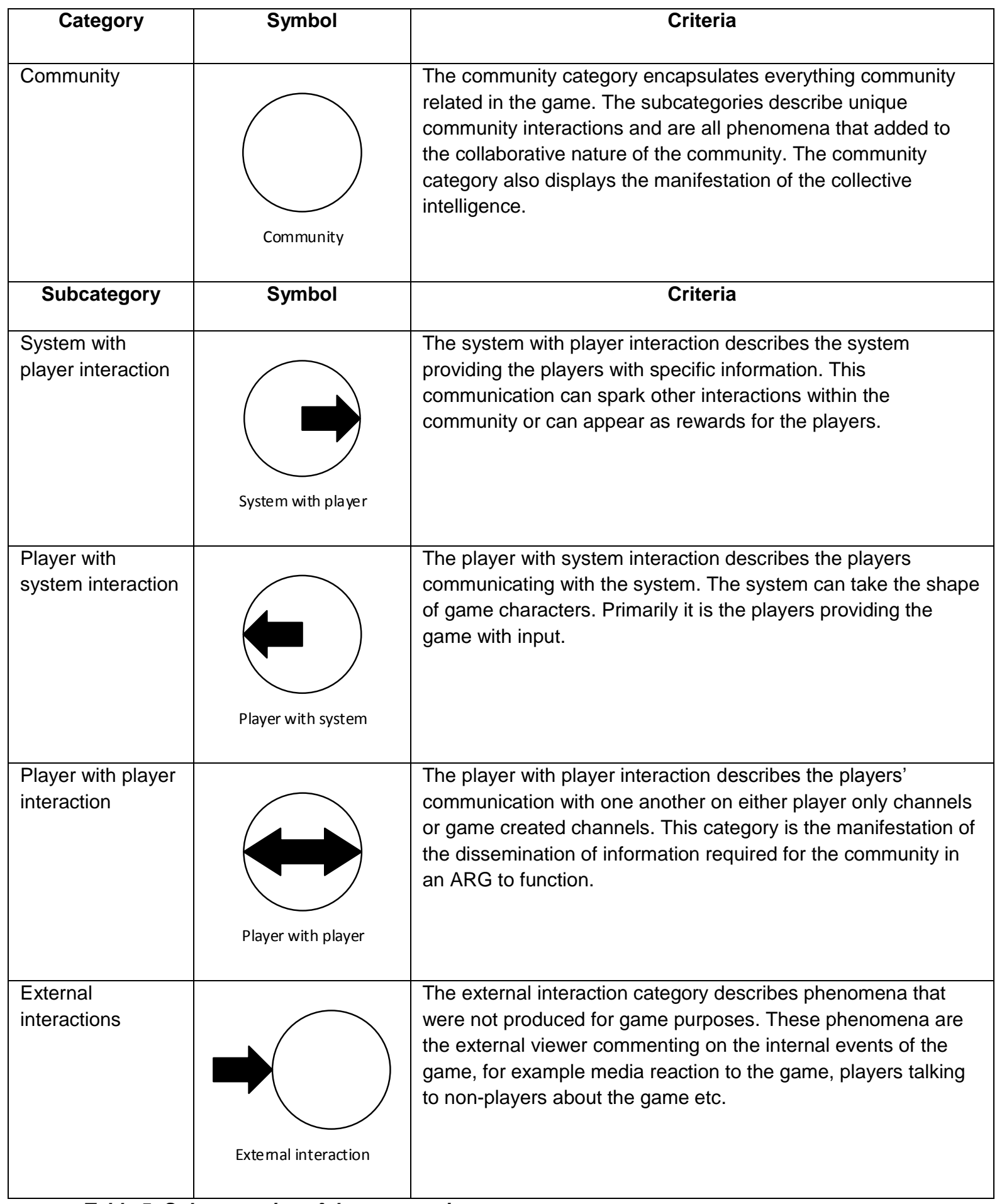

Table 5: Subcategories of the community category 


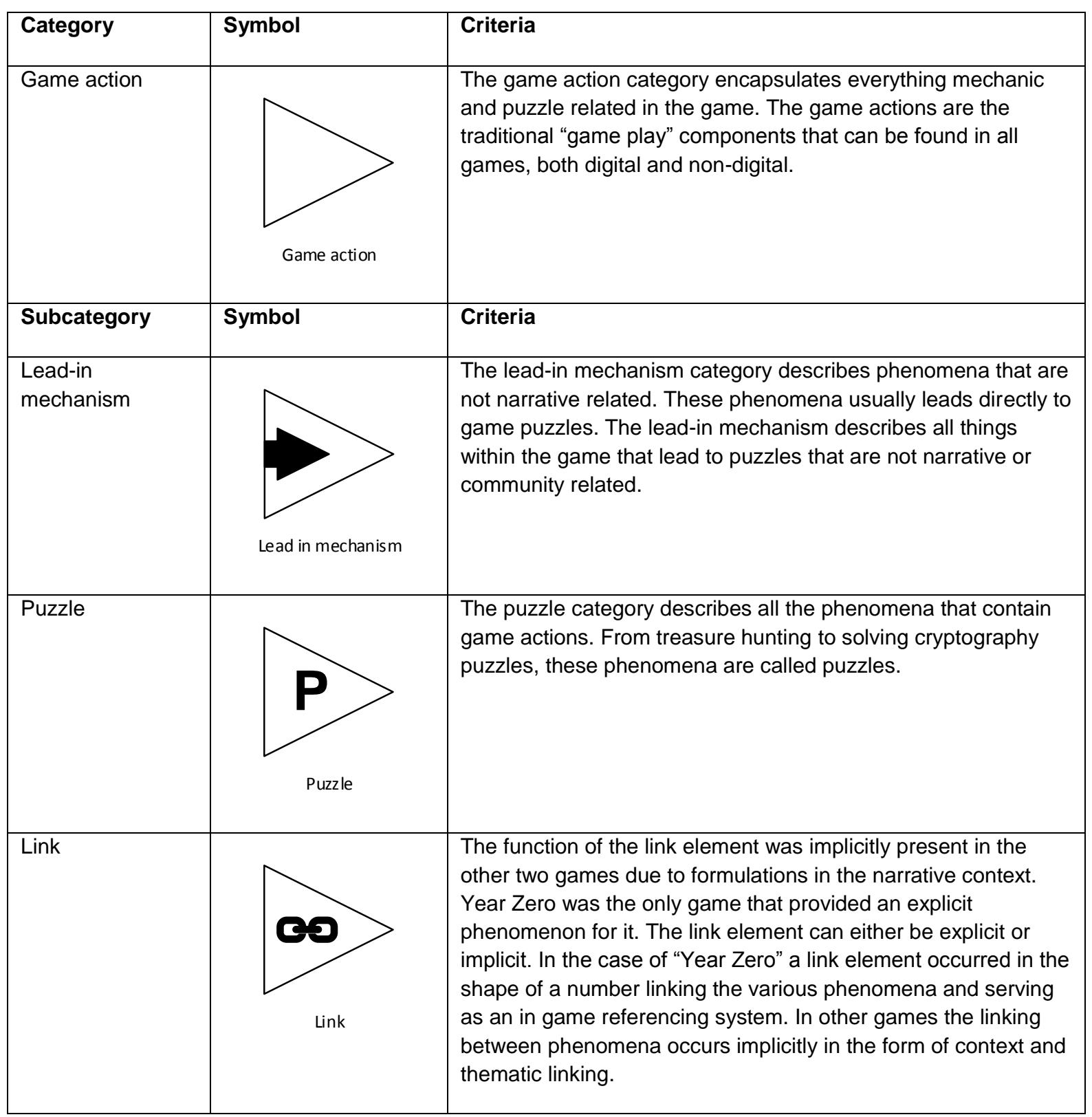

Table 6: Subcategories of the game action category 


\begin{tabular}{|l|l|}
\hline Miscellaneous & Criteria \\
\hline Hook & $\begin{array}{l}\text { The hook category describes a phenomenon that provides non- } \\
\text { players with clues that draw them into the game and turns them } \\
\text { into players. Any phenomenon can be categorised as a hook as } \\
\text { long as its function adheres to the criteria. }\end{array}$ \\
\hline Complete element & $\begin{array}{l}\text { The complete element describes a combination of the narrative } \\
\text { hook, lead-in mechanism, puzzle and narrative reward. The } \\
\text { existence of this element was due to the structure of the game } \\
\text { summaries. A single sentence recounted by the guide author } \\
\text { can contain all the above-mentioned phenomena. Instead of } \\
\text { breaking up the sentence into multiple sentences so the } \\
\text { categorisation can be applied, the complete element was used } \\
\text { to describe the combined phenomena. }\end{array}$ \\
\hline
\end{tabular}

Table 7: Miscellaneous categories

\section{Findings informing the creation of the conceptual framework}

Each case was analysed using the techniques and protocols described above. After each case study a summary was produced for each of the three ARG analysed. Detailed analysis of each case summary (game summary) produced the relationships and links between the various categories and subcategories. This analysis produced diagrams that abstractly describe each component or phenomenon in each game (see Figure 1). These diagrams or structures repeated throughout each game. Structures formed through relationships and linking but many of these structures also interlinked over phases or weeks of the game. An example of a single week from Year Zero can be seen in Figure 2. The numbering below each category and subcategory image linked directly back to a phenomenon found within the game summaries found in De Beer (2015).

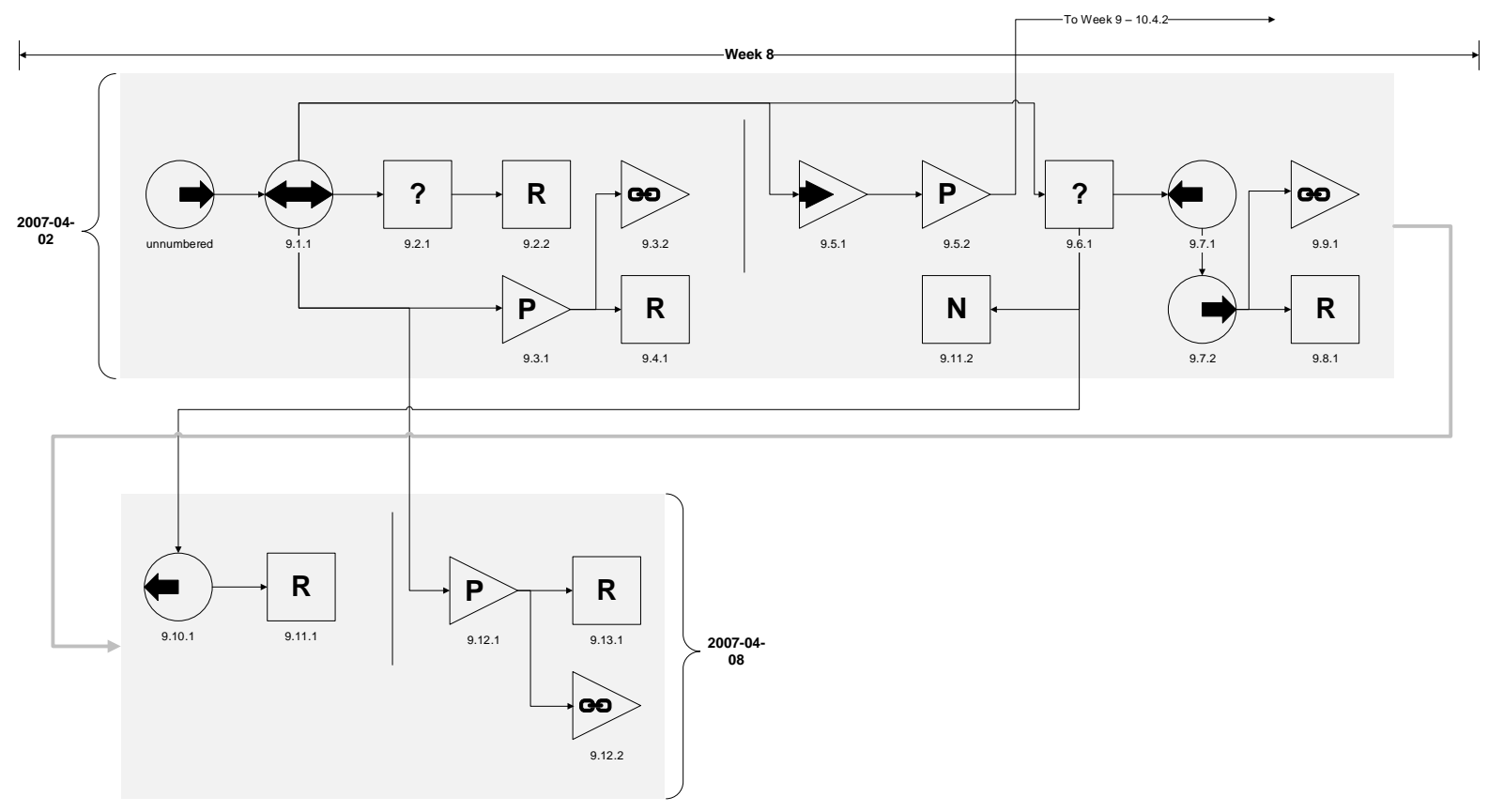

Figure 2: Example diagram of a single week in Year Zero

Each ARG provided a different construct that was an abstraction (in the form of a diagram) of each game. The abstractions provided an understanding of each game's unique phenomena and the 
relationship between these phenomena. Figure 3 shows the summary diagram of the game, Year Zero. The summary diagram was compiled from the complete diagram of which Figure $\mathbf{2}$ is only a single piece.

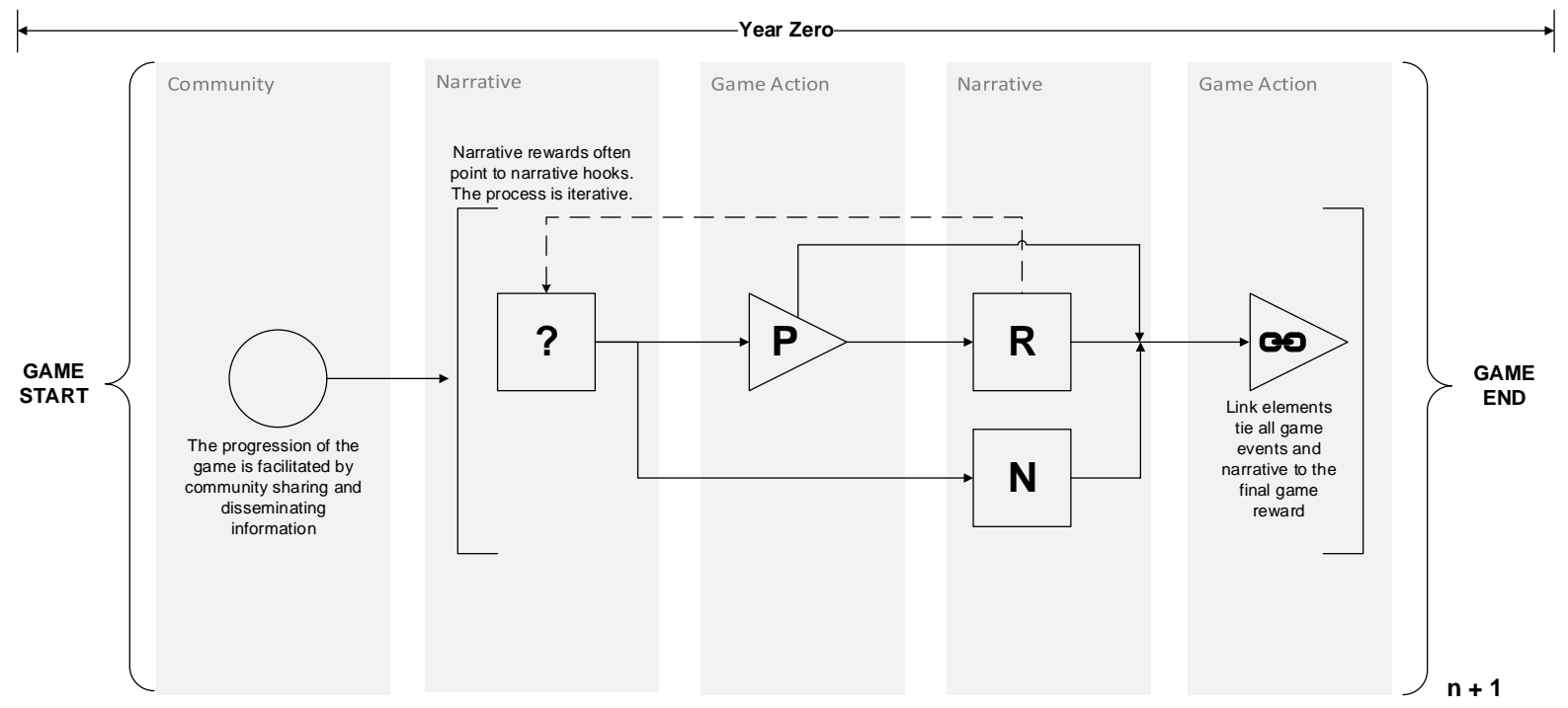

Figure 3: The summary diagram of one of the three games, Year Zero

Figure 3 describes the events and functioning of Year Zero as a whole in terms of narrative, game actions and community interaction in an abstract way. As shown on the left of Figure 3 , the community participation was a primary driving force in the game with the players sharing and spreading the game information, analysing narrative, following the clues of the narrative to puzzles or more narrative. Narrative found throughout the game could contain narrative hooks which either pointed to narrative pieces (for context), game actions (specifically puzzles) and narrative rewards. The puzzles in the game lead to narrative rewards which were usually marked with an explicit link element. The above described abstraction repeated throughout the game.

Combining the three constructs from the analysed ARGs was done by investigating similarities as well as differences between the way the categories and subcategories interact with one another.

The conceptual framework in Figure $\mathbf{4}$ was developed by generalizing the abstraction of each game. Combining the three diagrams produced the conceptual framework in Figure 4. 


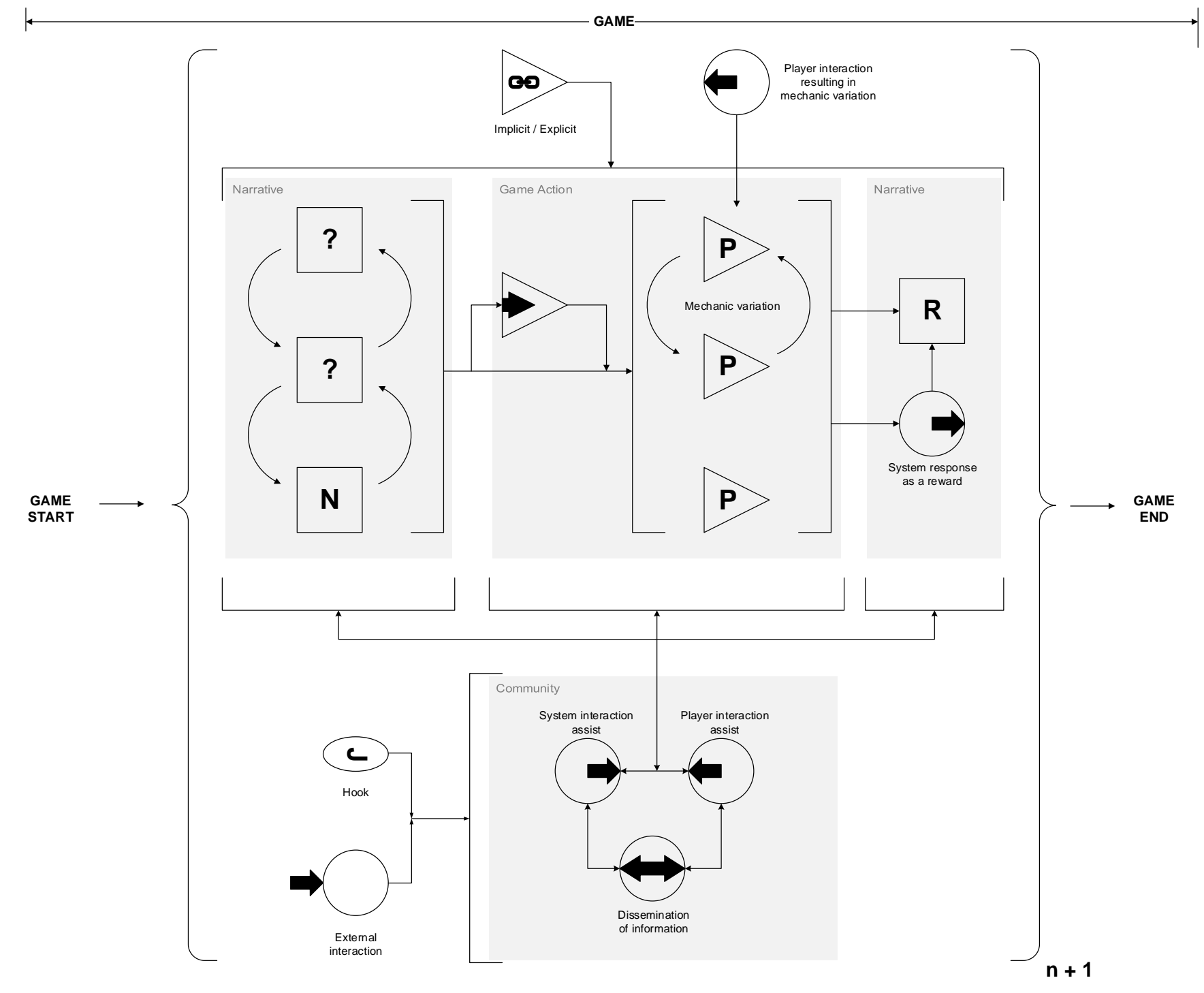

Figure 4: The conceptual framework for developing and analysing ARGs. 


\section{Explaining the conceptual framework}

The primary driving force that moves an ARG forward is the players participating in the game. By participating in the game, the players are playing it. This is not a unique feature of ARGs and is something that is found within all games. Without players a game cannot exist. The forward force of the player participation in ARGs is described in the "Community" categorisation in Figure 4. The "system interaction assist", "player interaction assist" and the "dissemination of information" are all phenomena that can be found in the three ARGs used in this study. The community collaboration and interaction has the largest influence on "game action" category within the framework. The community is the driving force; the players discover the narrative hooks and pieces, the community analyses it and discovers the puzzles but without the players solving the puzzles, the game will not be able to progress. The community category requires iterative interaction between the players and the system. The passing of information between the players and between the players and the system is the forward motion of the ARG in terms of interaction and narrative.

The narrative of the ARG is the "fuel" for the forward motion. Without the narrative, the players will not be able to share the information with one another, there will be no interest in solving puzzles because there will be no reward and there will be no context for the players to use for interpretation of game actions and narrative. The first narrative category in Figure 4 provides a representation of how the narrative is provided to the player. Narrative is provided in the form of narrative pieces or narrative hooks. The narrative pieces can contain narrative hooks. Narrative hooks can provide players with more narrative hooks and these hooks can point the game action component of the ARG.

Individual phenomena are categorised and subcategorised as the game actions within the ARG. The game actions can be preceded by a very specific phenomenon that directly points to a game action. This specific phenomenon is categorised as a lead-in mechanism. The narrative hook can also directly result in the players discovering game actions to complete. Completing the game actions requires the full community interaction. Even if a single player can solve the puzzle, that player is still required to share the solution with the rest of the players as well as what they received as the reward. By doing this, players add to the game narrative, establish game context and provide opportunity for game progression. Within the game action category, the game mechanics can also experience variation. The game mechanic variation is sparked by the players becoming used to the current mechanic. A level of boredom develops, and even though the ARG is primarily about the narrative, the game must remain engaging. Because of this, the game can introduce game mechanic variations. This can lead to a puzzle leading to a similar puzzle but with different mechanics (mechanic variation).

By completing the game actions, the players once again receive narrative, this time in the form of narrative reward. The narrative reward provides the players with narrative specific to the game's narrative and expands the context of the game. The players can also receive a system response that can form part of the narrative reward. This system response is not necessarily narrative. The system response makes the players a part of the complete game experience. For example, besides giving the players a narrative reward, the system mentions specific players by name. Even though the players do not become an intricate part of the narrative, the mentioning of the players by name provides the players with a level of ownership. The players experience that they had an influence on the events of the game because the game directly acknowledges them.

The discussed flow of narrative to game action back to narrative, facilitated and driven by the player community is described in the conceptual framework. The detailed components within the framework provide proposed examples of how this flow can be achieved within an ARG. As with the summary diagrams for each game, the $n+1$ in the diagrams implies that the diagram can be cycled through multiple times but must occur at least once in a game. 


\section{Conclusion}

The different types of information sources available for ARGs are found across multiple media. The gathering of this various information sources requires in depth knowledge of how ARGs function. These sources include game guides created by players as a means of catching up and cataloguing their experience, game forums used by the players to investigate and solve puzzles and game content created by the game designers. By integrating these various digital sources into a single, accurate game narrative a detailed summary can be established of the specific ARG from the players' perspective. The summary includes the types of game events, how the players played as well as what the game narrative was.

By analysing these game narratives or game summaries using constant comparative analysis, certain categories and subcategories could be identified. The categories were identified from both literature and the analysis of the game summaries. The subcategories arose through microanalysis of the game summaries.

For each game, a detailed diagram was then created to establish relationships and links between these categories and subcategories. The complete game diagrams were then abstracted into a single diagram which summarised the games. Finally, the three game diagrams were used to inform the creation of a conceptual framework that effectively described all three games. The conceptual framework can describe how an ARG functions and how the different pieces of information distributed and created during an ARG are linked to one another. By understanding the functioning of the conceptual framework, one can understand how an ARG functions.

The understanding granted by the conceptual framework and the process used to develop the framework can enable and ease the creation of ARGs for specific tasks such as teaching and learning. ARGs can be excellent platforms for learning and practicing of $21^{\text {st }}$ century literacies as stated by Bonsignore et al (2012) and can lead to creating ARGs specifically designed for information literacy amongst other things. The researcher proposed the creation of an ARG to teach library literacy in 2013 (De Beer and Holmner, 2013) and a current project of the researcher and his colleagues focuses on the creation of an ARG for exercising information literacy in the library.

The conceptual framework can aid researchers and developers in designing and studying ARGs. Using the framework will provide researchers a definite starting point in this endeavour. It is also hoped that the conceptual framework will not only be used in ARGs but will be used in developing a new type of game that can use the strengths of ARGs while avoiding the limitations and challenges of traditional ARGs.

\section{Bibliography}

Bono, J.J. and Breeze, M. (2008), "What is an ARG? : ARGology", available at: http://www.argology.org/_what-is-an-arg/ (accessed 16 September 2014).

Bonsignore, E., Hansen, D., Kraus, K. and Ruppel, M. (2012), “Alternate Reality Games as Platforms for Practicing 21st-Century Literacies", International Journal of Learning and Media, Vol. 4 No. 1, pp. 25-54.

Chess, S. and Booth, P. (2014), "Lessons down a rabbit hole: Alternate reality gaming in the classroom", New Media \& Society, Vol. 16 No. 6, pp. 1002-1017. 
De Beer, K. (2015), “Analysing Alternate Reality Games based on game design theory to propose a conceptual framework", Unpublished MIS dissertation, University of Pretoria.

De Beer, K. and Holmner, M. (2013), "The design of an alternate reality game as capstone course in a multimedia post-graduate degree", Proceedings of the IATUL Conferences, available at: http://docs.lib.purdue.edu/iatul/2013/papers/30.

Dena, C. (2008), "Emerging Participatory Culture Practices Player-Created Tiers in Alternate Reality Games", Convergence: The International Journal of Research into New Media Technologies, Vol. 14 No. 1, pp. $41-57$.

Gurzick, D., White, K.F., Lutters, W.G., Landry, B.M., Dombrowski, C. and Kim, J.Y. (2011), "Designing the Future of Collaborative Workplace Systems: Lessons Learned from a Comparison with Alternate Reality Games", Proceedings of the 2011 iConference, ACM, New York, pp. 174-180.

Hakulinen, L. (2013), “Alternate Reality Games for Computer Science Education”, Proceedings of the 13th Koli Calling International Conference on Computing Education Research, ACM, New York, pp. 43-50.

Hansen, D., Bonsignore, E., Ruppel, M., Visconti, A. and Kraus, K. (2013), “Designing Reusable Alternate Reality Games", Proceedings of the SIGCHI Conference on Human Factors in Computing Systems, ACM, New York, pp. 1529-1538.

Kim, J., Lee, E., Thomas, T. and Dombrowski, C. (2009), "Storytelling in new media: The case of alternate reality games, 2001-2009", First Monday, Vol. 14 No. 6, available at: http://journals.uic.edu/ojs/index.php/fm/article/view/2484 (accessed 27 February 2015).

Kim, J.Y., Allen, J.P. and Lee, E. (2008), "Alternate Reality Gaming", Communications of the ACM, Vol. 51 No. 2, pp. 36-42.

Martin, A., Thompson, B., Phillips, A., Alexander, B., Dena, C. and Barlow, N. (2006), IGDA ARG SIG - Alternate Reality Games White Paper, Whitepaper, IGDA ARG SIG, available at: http://archives.igda.org/arg/resources/IGDA-AlternateRealityGames-Whitepaper-2006.pdf. McGonigal, J. (2003a), "This is not a game: immersive aesthetics and collective play", Digital Arts \& Culture 2003 Conference Proceedings, presented at the Digital arts and culture, Melbourne, available at: http://itls.usu.edu/ bshelton/courses/instsim/readings/McGonigalImm_Aes_Coll_Play.pdf (accessed 25 February 2015). 
McGonigal, J. (2003b), "A real little game: The performance of belief in pervasive play", Proceedings of DIGRA's Level Up, available at: http://citeseerx.ist.psu.edu/viewdoc/summary?doi=10.1.1.124.2359 (accessed 16 February 2010).

McGonigal, J. (2004), “Alternate Reality Gaming: 'Life Imitates ARG”, Powerpointpresented at the MacArthur Foundation Board of Directors, Berkeley, November, available at: http://www.avantgame.com/McGonigal\%20ARG\%20MacArthur\%20Foundation\%20NOV\%20 04.pdf (accessed 20 February 2015).

McGonigal, J. (2007), "Why I Love Bees: a case study in collective intelligence gaming", in Salen, K. (Ed.), The Ecology of Games: Connecting Youth, Games, and Learning, MIT Press, Cambridge, pp. 199-227.

Örnebring, H. (2007), "Alternate reality gaming and convergence culture The case of Alias", International Journal of Cultural Studies, Vol. 10 No. 4, pp. 445-462.

Pickard, A.J. (2013), Research Methods in Information, Facet, London.

Salen, K. and Zimmerman, E. (2003), Rules of Play: Game Design Fundamentals, MIT Press, Cambridge.

Shenton, A.K. (2013), "Analysing of existing, externally created material", in Pickard, A.J. (Ed.), Research Methods in Information, Facet, pp. 251-260.

Strauss, A.L. and Corbin, J.M. (1998), Basics of Qualitative Research: Techniques and Procedures for Developing Grounded Theory, Sage Publications, Thousand Oaks.

Szulborski, D. (2005), This Is Not a Game: A Guide to Alternate Reality Gaming, First., New Fiction Publishing, Pennsylvania.

unfiction inc. (2002), "The unfiction glossary", available at: http://www.unfiction.com/glossary/ (accessed 28 February 2013).

Yin, R.K. (2013), Case Study Research: Design and Methods, Sage Publications, Los Angeles. 